\title{
Socioeconomic factors effecting polio vaccination in Pakistan
}

\author{
Sheeba Arooj ${ }^{1^{\star}}$, Sitwat $\mathrm{Ali}^{1}$, Nimra Baber ${ }^{1}$, Atif $A b b a s i^{2}$, Midhat Ali $^{3}$ \\ ${ }^{1}$ Institute of Social \& Cultural Studies, University of Punjab, Lahore, Pakistan; \\ *Corresponding Author: sarooj45@yahoo.com \\ ${ }^{2}$ Dapartment of Statistics, University of Azad Jammu \& Kashmir, Muzaffarabad, Pakistan \\ ${ }^{3}$ Department of Sociology, Bahauddin Zakria University, Multan, Pakistan
}

Received 29 March 2013; revised 30 April 2013; accepted 15 May 2013

Copyright (c) 2013 Sheeba Arooj et al. This is an open access article distributed under the Creative Commons Attribution License, which permits unrestricted use, distribution, and reproduction in any medium, provided the original work is properly cited.

\section{ABSTRACT}

Background: Child vaccinations are one of most cost effective health programs that have weakened a number of child morbidity and mortality rate all over the world. Pakistan is considered one of the major country of the world, where people especially children are bound by many harmful infectious diseases like polio, hepatitis, viral infections etc. The effectiveness of routine childhood immunization programs relies on multiple factors. Socio-economic determinants have the potential to affect immunization programs. The purpose of the present study was to determine the association between socio-economic factors and polio vaccination coverage among children in Pakistan. Methods: The study used data from the Pakistan demographic health survey (PDHS 2006-07 N 10023). The study focused on respondents who had births in last five years. Descriptive and inferential statistics were used to determine the association between variables. Spss version 20 was used for data analysis. A number of socioeconomic variables were used in chi square \& binary logistic regression model to check out their association with polio vaccination coverage. Results: Study shows that most dominant factors associated with polio vaccination coverage were region that is NWFP OR 3.48 (odd ratio) with $95 \%$ confidence interval (C-I 2.06 \& 3.13) \& Punjab OR 2.54 (C-I 2.062 \& 3.131), residence urban OR 1.626 (C-I $1.451 \& 1.822$ ), sex of child male OR 1.125 (C-I 1.008 \& 1.256), age of mother 25 - 34 years OR 1.11 (C-I 0.978 \& 1.276), wealth index rich OR 2.98 (C-I 2.55 \& 3.48), age of child 4 - 5 years OR 1.17 (C-I $0.899 \&$ 1.538), mo- ther's education higher OR 2.06 (C-I 1.776 \& 2.411), father's education higher OR 1.399 (C-I $1.221 \& 1.203)$,father's occupation professional OR 1.27 (C-I 0.929 \& 1.737). Conclusion: In developing countries like Pakistan most of the children remain unvaccinated because of many socio-economic constraints. Poor marginalized people have a low awareness regarding the importance of polio vaccine. Along with social hierarchies, educational attainment of parents is a strong indicator of defining awareness level regarding vaccination.

Keywords: Pakistan Demographic Health Survey; Polio Vaccination; Socioeconomic Factors; Children Less than 5 Years; Odd Ratio

\section{INTRODUCTION}

Poliomyelitis which is also called polio or infantile paralysis, is a highly infectious viral disease that can attack the central nervous system and it is characterized by symptoms that range from a mild non paralytic infection to total paralysis in just a few hours (Medical dictionary). There is no cure for polio once a person becomes infected. The treatment is usually focused on providing comfort, managing symptoms and avoiding complications [1]. Mass immunization campaigns are launched as a strategy to eradicate polio and usually these campaigns achieve high levels of vaccination coverage but achieving a high level of coverage is not enough because there are a lot of examples in the literature that the outbreaks of the polio have occurred in under vaccinated populations that we're living within highly vaccinated population [2]. The factors which have a statistically significant association with vaccination coverage include level of education, 
knowledge on vaccination, number of children within family, birth place, and advice on the next date of growth monitoring, opinion of health services provided in the area [3]. The vaccination coverage of children whose mothers have higher than primary education tends to be higher. Major reason for higher vaccination coverage among children of highly educated mothers is that they mostly belong to wealthier households. Therefore, another important factor closely related with maternal education in this regard is the economic standing of the family [4]. While maternal education is important in determining vaccination coverage among children, father's education may also be important [5]. Studies show that 99.1\% mothers had positive attitude towards vaccination, 87\% mothers were having a satisfactory level of knowledge regarding vaccination. Vaccination coverage is higher in those having vaccination card (69.7\%). Full vaccination coverage has a strong association with knowledge of vaccination and vaccination through private health facility [6]. The uptake of vaccination services is determined not only by provision of the services of immunization but also by other factors which include knowledge and attitude of mothers towards vaccination, density of health workers, accessibility to vaccination clinics and availability of safe needles and syringes [7].

\section{Situation in Pakistan}

In 2012, 58 polio cases were reported in Pakistan out of which four were recorded in the province of Sindh. The first polio case has been detected in Karachi a boy who never vaccinated against polio [8]. In 2012, there were only three countries (Afghanistan, Nigeria and Pakistan) which remained affected by polio, while their number was 125 in 1988 [9]. In the most populous developing countries, the actual numbers of unvaccinated infants are highest although some of which have fairly high rates of immunization coverage [10].

In Peshawar, 83.7\% children were vaccinated in national immunization days while $94.7 \%$ children had taken the polio vaccine at least once and $5.3 \%$ children had not taken the polio vaccine at all. The major reasons of no vaccination included unavailability of vaccination (63.36\%), commitment of child's mother somewhere else (3.3\%), misconception that vaccine can cause sterility (3.3\%) and child's ill health (5.8\%) [11]. Many studies have focused on the factors that may affect immunization coverage rates. The results of these studies show that Low parental, specifically maternal literacy and knowledge regarding vaccination and immunization schedule, lower socioeconomic status, and residence in rural areas are strongly associated with low immunization coverage [12]. The reasons for failure to achieve polio eradication also show the importance of non-health sector issues such as access in war and conflict zones, refusal of parents to vaccinate their children and problems with cross-border movement of nomadic populations from Afghanistan [13].

\section{METHODOLOGY}

The present study is a secondary analysis of the Pakistan Demographic and Health Survey (PDHS) 2006-07 which is a nationally representative data of 10,023 respondents.

\subsection{Ethical Approval}

This study was approved by National Institute of Population Studies.

\subsection{Inclusion and Exclusion Criteria}

The study included those 5349 respondents who had births in last five years as it only focused on children of five years or less when the polio vaccination is completed. This was done through computing the original variable in data and including only those respondents who had births in last five years.

\subsection{Analysis}

Data were entered on spread sheet and analyzed using SPSS software version 20. Both descriptive (percentage) and inferential (chi-square \& bivariate logistic regression model) statistics were used for data analysis.

\subsection{Measures}

The present study used one dependant variable polio vaccination coverage for which four variables of polio vaccination doses $0,1,2,3$ were computed into polio vaccination coverage and recoded into full vaccination \& no vaccination. The independent variable of the study was socio-economic status. Socio-economic status refers to both absolute and relative levels of wealth and the power and prestige that is closely associated with wealth, which may be reflected in measures of income, accumulated economic assets, occupational status, and educational attainment, among other measures [14]. The present study used Region, Place of residence, Mother's level of education (recoded into no education, primary and higher), Father's level of Education (recoded into no education, primary and higher), Father's Occupation (recoded into did not work, professional work and manual work), Wealth index (recoded into poor, middle and Rich), Age of Mother (recoded into 15 - 24, 25 - 34 and $35 \&$ above) as the indicators of socio-economic status.

\section{RESULTS}

Table 1 shows that 42.5\% people belonged to Punjab. 
Table 1. Frequency distribution of socio-economic factors affecting vaccination coverage among children.

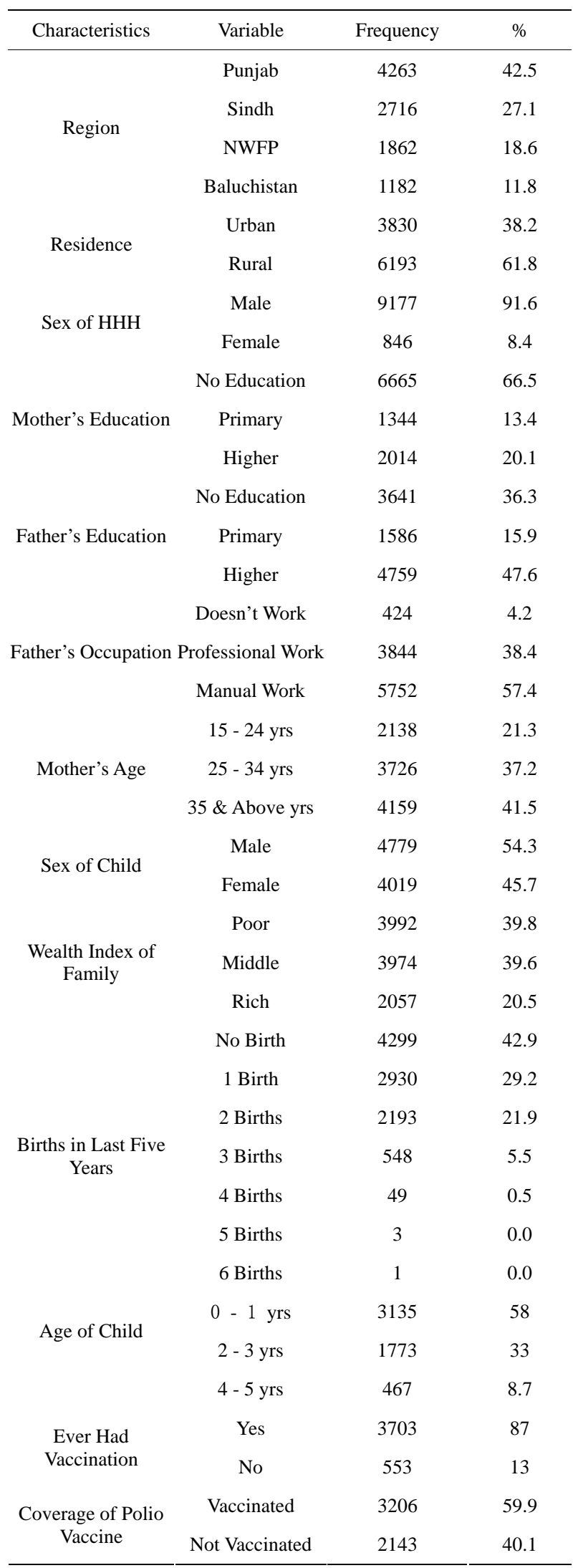

People who live in rural area were $61.8 \%$ while $38.2 \%$ lived in urban areas. The houses that were headed by a male were $91.6 \%$. Mothers who did not receive any education were $66.5 \%$. $47.6 \%$ fathers received higher education. Fathers who were doing manual work were $57.4 \%$. $41.5 \%$ of mothers were of $35 \&$ above years of age, $45.7 \%$ children were male while $39.8 \%$ children were female. $39.8 \%$ families were on poor level in wealth index whereas $39.6 \%$ were of middle class. $42.9 \%$ women had no birth in last five years while $58 \%$ children were of 0 - 1 years of age. $87.0 \%$ children ever received vaccination \& $13.0 \%$ children never received any vaccination. Children who were vaccinated by polio vaccination were $59.9 \%$

Table 2 shows that the coverage of polio vaccination among children is strongly associated with region, type of place of residence, educational level of the mother, educational level of father, father's occupation and wealth index of the family. The variables of mother's

Table 2. Chi square results for association between socioeconomic factors and polio vaccination coverage.

\begin{tabular}{|c|c|c|c|}
\hline Characteristics & Variables & Chi Square Value & P value \\
\hline \multirow{4}{*}{ Region } & Punjab & \multirow{4}{*}{131.149} & \multirow{4}{*}{0.000} \\
\hline & Sindh & & \\
\hline & NWFP & & \\
\hline & Baluchistan & & \\
\hline \multirow{2}{*}{ Residence } & Urban & \multirow{2}{*}{70.458} & \multirow{2}{*}{0.000} \\
\hline & Rural & & \\
\hline \multirow{2}{*}{ Sex of $\mathrm{HHH}$} & Male & \multirow{2}{*}{3.149} & \multirow{2}{*}{0.076} \\
\hline & Female & & \\
\hline \multirow{3}{*}{$\begin{array}{l}\text { Mother's } \\
\text { Education }\end{array}$} & No Education & \multirow{3}{*}{169.818} & \multirow{3}{*}{0.000} \\
\hline & Primary & & \\
\hline & Higher & & \\
\hline \multirow{3}{*}{ Father's Education } & No Education & \multirow{3}{*}{96.874} & \multirow{3}{*}{0.000} \\
\hline & Primary & & \\
\hline & Higher & & \\
\hline \multirow{3}{*}{$\begin{array}{l}\text { Father's } \\
\text { Occupation }\end{array}$} & Doesn't work & \multirow{3}{*}{35.911} & \multirow{3}{*}{0.000} \\
\hline & $\begin{array}{l}\text { Professional } \\
\text { Work }\end{array}$ & & \\
\hline & Manual Work & & \\
\hline \multirow{3}{*}{ Mother's Age } & 15 - 24 years & \multirow{3}{*}{15.684} & \multirow{3}{*}{0.000} \\
\hline & 25 - 34 years & & \\
\hline & $\begin{array}{c}35 \& \text { above } \\
\text { years }\end{array}$ & & \\
\hline \multirow{2}{*}{ Sex of Child } & Male & \multirow{2}{*}{4.421} & \multirow{2}{*}{0.036} \\
\hline & Female & & \\
\hline \multirow{3}{*}{ Wealth Index } & Poor & \multirow{3}{*}{216.898} & \multirow{3}{*}{0.000} \\
\hline & Middle & & \\
\hline & Rich & & \\
\hline
\end{tabular}


age, sex of child are not associated with the coverage of polio vaccination among children.

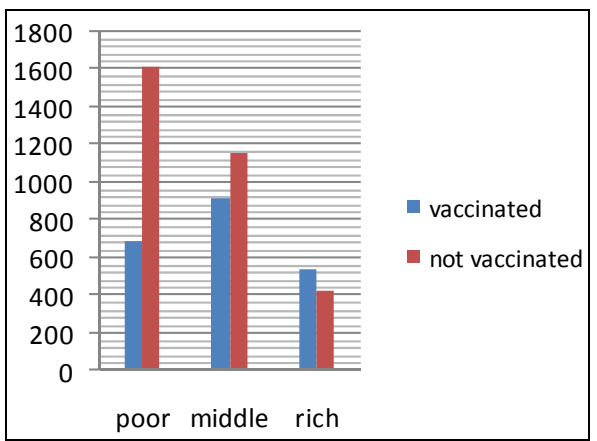

Table 3 describes that as far as polio coverage is concerned odd of NWFP province were 3.48 times higher (C-I 2.06 \& 3.13) whereas in Punjab odds were 2.54 (C-I $2.062 \& 3.131$ ) times higher than balochistan. Odds of urban areas of Pakistan were 1.626 (C-I 1.451 \& 1.822) times higher than rural areas. Residential differences are significantly associated with polio vaccination coverage. Odds of male household head were. 827 times lower (C-I $0.670 \& 1.020$ ) so male members are less likely to make decision regarding vaccination of children. People belonging to rich class of society are 2.986 (OR) times more likely to vaccinate their children than poor class (C-I $2.55 \& 3.48$ ). Odds of middle age mothers (25 - 34 years) were 1.117 (C-I 0.978 \&1.276) times higher than older women (35 \& above). Odds of children between age of 4 - 5 years were 1.176 times higher (C-I $0.899 \& 1.538$ ) than of 1 year children so children of younger age receive polio vaccination higher. Occupation of father is strongly associated with receiving polio vaccination as odds of professional workers were 1.270 times higher (C-I $0.929 \& 1.737$ ) than those who didn't work. Educational status of women is associated with receiving polio vaccination as odds of higher education of mothers were 2.069 times higher (C-I 1.776 \& 2.411) \& primary education OR 1.511 than mother having no education. Odds of higher education of father were 1.399 times higher (C-I 1.221 \& 1.203) \& primary education OR 1.211 than no education. Therefore, education of father is strongly associated with polio vaccination coverage of children.

\section{DISCUSSION}

This study aimed to discover the socio economic factors affecting coverage of polio vaccine among children in Pakistan. The bivariant analysis shows that the socioeconomic factors affect the coverage of polio vaccine. It was found that region had a strong association with polio vaccination coverage with Punjab and NWFP with higher levels of vaccination coverage. While in
Table 3. Socioeconomic factors against polio vaccination coverage.

\begin{tabular}{|c|c|c|c|c|}
\hline \multirow{2}{*}{ Characteristics } & & \multirow{2}{*}{$\begin{array}{c}\begin{array}{c}\text { Polio } \\
\text { vaccination }\end{array} \\
\text { Odd ratio }\end{array}$} & \multicolumn{2}{|c|}{$95 \%$ C-I } \\
\hline & & & Lower & Upper \\
\hline \multirow{4}{*}{ Region $^{*}$} & Punjab & 2.541 & 2.062 & 3.131 \\
\hline & Sind & 2.118 & 1.705 & 2.631 \\
\hline & NWFP & 3.488 & 2.784 & 4.369 \\
\hline & Baluchistan & 1 & & \\
\hline \multirow{2}{*}{ Place of residence ${ }^{*}$} & Urban & 1.626 & 1.451 & 1.822 \\
\hline & Rural & 1 & & \\
\hline \multirow{2}{*}{ Sex of $\mathrm{HHH}^{* *}$} & Male & 0.827 & 0.670 & 1.020 \\
\hline & Female & 1 & & \\
\hline \multirow{2}{*}{ Sex of child* } & Male & 1.125 & 1.008 & 1.256 \\
\hline & Female & 1 & & \\
\hline \multirow{3}{*}{ Wealth index ${ }^{*}$} & Middle & 1.862 & 1.644 & 2.109 \\
\hline & Rich & 2.986 & 2.557 & 3.486 \\
\hline & Poor & 1 & & \\
\hline \multirow{3}{*}{ Age of mother ${ }^{*}$} & $15-24$ & 0.848 & 0.724 & .994 \\
\hline & $25-34$ & 1.117 & 0.978 & 1.276 \\
\hline & 35 \& above & 1 & & \\
\hline \multirow{3}{*}{ Age of child } & $2-3$ & 1.024 & 0.869 & 1.206 \\
\hline & $4-5$ & 1.176 & 0.899 & 1.538 \\
\hline & 1 year & 1 & & \\
\hline \multirow{3}{*}{ Father occupation ${ }^{*}$} & Professional & 1.270 & 0.929 & 1.737 \\
\hline & Mannual & 0.898 & 0.659 & 1.224 \\
\hline & Didn't work & 1 & & \\
\hline \multirow{3}{*}{ Mother education ${ }^{*}$} & Primary & 1.551 & 1.317 & 1.827 \\
\hline & Higher & 2.069 & 1.776 & 2.411 \\
\hline & No education & 1 & & \\
\hline \multirow{3}{*}{ Father education ${ }^{*}$} & Primary & 1.211 & 1.022 & 1.436 \\
\hline & Higher & 1.399 & 1.221 & 1.603 \\
\hline & No education & 1 & & \\
\hline
\end{tabular}

*Significantly associated p value less than $0.05 ;{ }^{* *}$ Household head.

Balochistan only $22.2 \%$ children are vaccinated. The reason for this low rate of vaccination coverage might be the problems of law and order situation in the province and inappropriate facilities of polio vaccination. Another factor can be the lower level of education in the province which is 34 percent against the national literacy rate of 52 percent as cited in Daily Times, 2007 [15]. The study concluded that mother's level of education is strongly associated with polio vaccination coverage. The mothers with higher education vaccinated their children more than the mothers with no education or lower level of education. Mothers who are not educated had three times higher risk to have not immunized their children than 
those mothers who had secondary and higher education [16]. The results also show a strong association between wealth index of the family and polio vaccination coverage. This may be due to the higher level of education among families with high economic status which leads to better awareness of the importance of polio vaccination. The association between place of residence and polio vaccination coverage is very strong. The parents of urban areas vaccinated their children more than the parents of rural areas. This may be due to the better immunization facilities in urban areas and higher levels of education and awareness consistent with previous researches [17]. Education level and occupation of child's father is strongly associated with coverage of polio vaccination because awareness of importance of polio vaccination is very important for both parents. Highly educated fathers are more likely to give much more importance to vaccinate their children and make efforts for the completion of their children's polio vaccination.

\section{CONCLUSION}

Present study investigated that socioeconomic \& socio demographic factors impacts on polio vaccination coverage as upper class people \& people of higher educational background had better knowledge of communicable diseases \& its prevention through vaccination. Age is an important indicator in defining awareness level of parents regarding immunization. Most importantly, in Pakistani patriarchal setup male children are recipient of vaccination more than female children.

\section{LIMITATIONS}

An important limitation of the present study is that it did not include the analysis of local superstitions and myths related to polio vaccination among the people especially in rural areas. These superstitions are a cause of failure of vaccination campaigns. The social issues that are prevailing in Pakistan like law and order situation, terrorism, killing of vaccinators and the effects of these killings on polio vaccination campaigns are not a part of this study. The lack of awareness about the importance of polio vaccination and the problems related with non-immunization, the performance of the vaccination staff is also not the part of this study.

\section{RECOMMENDATIONS}

The superstitious attitudes of people that affect the full coverage of polio vaccine can be eradicated through involving religious leaders \& thinkers in awareness programs who are a very important source of opinion formation especially in rural areas. The attitude and effi- ciency of the vaccinators are of important concern so, their training and monitoring are very important. Involvement of media in order to increase awareness about the importance of vaccination is needed to be enhanced for effective results.

\section{REFERENCES}

[1] Crost, P. (2012) What is polio? What causes Polio? Medical News Today. http://www.medicalnewstoday.com/articles/155580.php

[2] William, M.W., Peter, J.W. and Gilbert, B. (2009) Factors associated with missed vaccination during mass immunization campaigns. Journal of Health Population \& Nutrition, 27, 358-367.

[3] Maina, C., Karanja, S. and Kombich, J. (2012) Immunization coverage and its determinants among children aged 12 - 23 months in a peri-urban area of Kenya. The Pan African Medical Journal.

[4] Kirti, V., Reeve, V. and Sonalde, D. (2012) Linkages between maternal education and childhood immunization in India. Social Science and Medicine, 75, 331-339. doi:10.1016/j.socscimed.2012.02.043

[5] Caldwell, J.C. and McDonald, P. (1982) Influence of maternal education on infant and child mortality: Levels and causes. Health Policy and Education, 2, 251-267. doi:10.1016/0165-2281(82)90012-1

[6] Odusanya, O., Alufohai, E., Francois, P. and Meurice, V. (2008) Determinants of vaccination coverage in rural Nigeria. BMC Public Health, 8, 381. doi:10.1186/1471-2458-8-381

[7] Torun, S.D. and Bakirci, N. (2006) Vaccination coverage and reasons for non-vaccination in a district of Istanbul. BMC Public Health, 6.

[8] (2013) Year first polio case detected in Karachi. http://dawn.com/2013/02/02/years-first-polio-case-detect ed-in-karachi/

[9] (2012) WHO fact sheet N 114 poliomyelitis.

[10] United Nations Childrens Fund (2009) Monitoring the situation of children and women: Child survival and health. United States of America, New York.

[11] Naeem, M., Zia Ul Islam, M., Adil, M., Ayasha, K., Usman, M. and Maria, S. (2012) Coverage and causes of non immunization in national immunization days for polio; a consumer and provider perspective study in pashawar. Journal of Postgraduate Medical Institute, 26, 4854.

[12] Phukan, R.K., Barman, M.P. and Mahanta, J. (2009) Factors associated with immunization coverage of children in Assam, India: Over the first year of life. Journal of Tropical Pediatrics, 55, 249-252. doi:10.1093/tropej/fmn025

[13] State of Pakistan's Children (2006) Islamabad: Society for the protection of the rights of the child (SPARC). http://www.sparcpk.org/publications/sopc_2006

[14] Paula, B., Catherine, C., Kristen, M., Susan, E. and Gilberto, C. (2001) Measuring socioeconomic status/position in studies of racial/ethnic disparities. Maternal and Infant 
Health. Public Health Reports, 116.

http://www.ncbi.nlm.nih.gov/pmc/articles/PMC1497365/ pdf/12042609

[15] (2007) Baluchistan home to lowest-literacy rate population in Pakistan. Daily Times, 7-14.

http://www.dailytimes.com.pk/default.asp?page=2007\%5 C06\%5C12\%5Cstory 12-6-2007 pg7 14
[16] Soma, B.C., Abu, D. and Faisul, A. (2001) Factors affecting childhood immunization in Bangladesh. The Pakistan Development Review, 40, 57-70.

http://www.pide.org.pk/pdf/PDR/2001/Volume1/57-70

[17] Suresh, S. (2013) Immunization coverage in India. http://www.iegindia.org/workpap/wp283 